\title{
Potential impact of climate change on the species richness of subalpine plant species in the mountain national parks of South Korea
}

Pradeep Adhikari, Man-Seok Shin, Ja-Young Jeon, Hyun Woo Kim, Seungbum Hong and Changwan Seo*

\begin{abstract}
Background: Subalpine ecosystems at high altitudes and latitudes are particularly sensitive to climate change. In South Korea, the prediction of the species richness of subalpine plant species under future climate change is not well studied. Thus, this study aims to assess the potential impact of climate change on species richness of subalpine plant species (14 species) in the 17 mountain national parks (MNPs) of South Korea under climate change scenarios' representative concentration pathways (RCP) 4.5 and RCP 8.5 using maximum entropy (MaxEnt) and Migclim for the years 2050 and 2070.

Results: Altogether, 723 species occurrence points of 14 species and six selected variables were used in modeling. The models developed for all species showed excellent performance (AUC $>0.89$ and TSS $>0.70$ ). The results predicted a significant loss of species richness in all MNPs. Under RCP 4.5, the range of reduction was predicted to be $15.38-94.02 \%$ by 2050 and $21.42-96.64 \%$ by 2070 . Similarly, under RCP 8.5 , it will decline $15.38-97.9 \%$ by 2050 and $23.07-100 \%$ by 2070. The reduction was relatively high in the MNPs located in the central regions (Songnisan and Gyeryongsan), eastern region (Juwangsan), and southern regions (Mudeungsan, Wolchulsan, Hallasan, and Jirisan) compared to the northern and northeastern regions (Odaesan, Seoraksan, Chiaksan, and Taebaeksan).

Conclusions: This result indicates that the MNPs at low altitudes and latitudes have a large effect on the climate change in subalpine plant species. This study suggested that subalpine species are highly threatened due to climate change and that immediate actions are required to conserve subalpine species and to minimize the effect of climate change.
\end{abstract}

Keywords: Climate change, Mountain national park, Species distribution model, Species richness, Subalpine species

\section{Background}

Anthropogenic impacts on the world's climate have been well recognized in recent decades. The emission of greenhouse gases (GHGs) is the primary agent responsible for global climate change. The world has experienced a temperature rise of $0.78{ }^{\circ} \mathrm{C}$ over the last century, and the temperature is projected to rise by $2.6-4.8^{\circ} \mathrm{C}$ by the end of this century (IPCC 2013). The ratio of temperature rise was not equal across the globe. In South Korea, the temperature has increased

\footnotetext{
* Correspondence: dharmascw@nie.re.kr

National Institute of Ecology, 1210 Geumgang-ro, Maseo-myeon, Seocheon, Chungcheongnam 33657, Republic of Korea
}

$1.8^{\circ} \mathrm{C}$ over the last 100 years, and the temperature is predicted to increase of $0.63{ }^{\circ} \mathrm{C}$ every 10 years until 2100 at the representative concentration pathways RCP 8.5 scenarios (Ministry of Environment 2018).

Species distribution models (SDMs) are empirical tools for simulating the spatial distribution of species, assessing the potential responses of organisms to climate change and determining the niche of species based on the environmental variables (Guillera-Arroita et al. 2015). Among the various SDMs, the maximum entropy (MaxEnt) model has a higher predictive accuracy while using a small amount of data on species occurrence and environmental variables (Pramanik et al.

(c) The Author(s). 2018 Open Access This article is distributed under the terms of the Creative Commons Attribution 4.0 International License (http://creativecommons.org/licenses/by/4.0/), which permits unrestricted use, distribution, and 
2018). Many SDMs have found an ignorance of dispersal limitations, assuming dispersal is either unlimited or null. These assumptions could be inaccurate and lead to over or underestimation of the future species distribution when considering the rate of climate change, dispersal capabilities of individual species, and landscape fragmentation (Engler and Guisan 2009). As a result, the potentially suitable and colonizable habitats could differ significantly. Therefore, to address this problem, we used the Migclim model to simulate plant dispersal under climate change and landscape fragmentation, which can seamlessly integrate the results yielded from the MaxEnt modeling and utilize the habitat suitability map as recommended by Engler et al. (2012).

The subalpine plant species are occurring in the subalpine zone, which is considered a narrow range of landscape consisting cold and humid climate. It is ranging from forest and limit to the timber line (Kong 2007). In South Korea, the subalpine zone varied from 500 to $1000 \mathrm{~m}$ above sea level (ASL) to 1600-1850 m ASL consists the habitat of several endemic (e.g., Abies koreana, Aconitum pseudolaeve, and Asperula lasiantha) and native species (e.g., Abies nephrolepis, Pinus pumila, and Taxus cuspidate), which are recognized as the valuable plants globally important (Kong et al. 2014; Noh et al. 2017). The subalpine plants have various ecological, economic, esthetic, and medicinal value (Dutta et al. 2014). In addition, subalpine plants have a fundamental role in maintaining the subalpine ecosystem. However, due to the climate change, the habitats of subalpine species and their species richness are declining. In Korean Peninsula, the rate of temperature rise is rapid compared to other regions (Lee 2011). Thus, the impact of climate change on subalpine plant species is expected to be high. Hence, regular studies are required to predict the potential distribution and species richness of subalpine species under climate changes for effective management planning that fits such changes (Díaz et al. 2015).

The impacts of climate change on the biodiversity of South Korea have been studied for several years, but most of the studies focused on the distribution of warm-adapted evergreen plants, which are mostly abundant in low altitude (Park et al. 2016a, 2016b; Park et al. 2017; Shin et al. 2018). Koo et al. (2015) studied the distribution of cold-tolerant broad-leaved plants, but it could not determine site-specific species richness. Therefore, this study aimed to determine the potential species richness of subalpine plant species in South Korea, focusing on the mountain national parks (MNPs). We first predicted the dispersal of some subalpine plant species and then derived the species richness in each MNP from the results of the individual species.

\section{Methods}

Study area

This study was conducted on the 17 MNPs of South Korea (Fig. 1 and Table 1). The study covers an area of $3236 \mathrm{~km}^{2}$, which is approximately $3.22 \%$ of the total area of the country (Korea National Park Service 2018). Hundreds of small hills and mountains (700-1950 m) are associated with the MNPs. The climate of South Korea is temperate, which is clearly distinguished into warm temperate (the southern coast and islands), temperate (the central and northern parts of South Korea), and cold temperate (the high mountains). The northern region is relatively cold and continental, but the southern region is warm and wet. The precipitation is usually high in summer and low in winter (mean annual rain fall $1200 \mathrm{~mm}$ ), with snow accumulation in the mountains.

The vegetation types are varied to elevation gradients. Deciduous broadleaf and pine forests are found up to $500 \mathrm{~m} \mathrm{ASL}$, and temperate broadleaf and mixed forests are found in 500-1150 m ASL, subalpine vegetation accessed from 500 to $1000 \mathrm{~m}$ ASL to $1600-1850 \mathrm{~m}$ ASL, and alpine vegetation is found at $1800-1950 \mathrm{~m}$ ASL (Kong 1998; Park et al. 2015). The overall floral diversity of South Korea exceeds 5200 species, and the overall faunal diversity is approximately 2500 species.

\section{Species occurrence data}

The presence of subalpine plant species was obtained from the field survey and different secondary sources (Korea National Arboretum 2004, 2005, 2006, 2007, 2008, 2009a, 2009b, 2011; National Institute for Environmental Research 2013; Kong et al. 2017). From the different national surveys, published papers, and our field visit, we collected species presence points of 14 subalpine plant species (Table 2) existing in subalpine

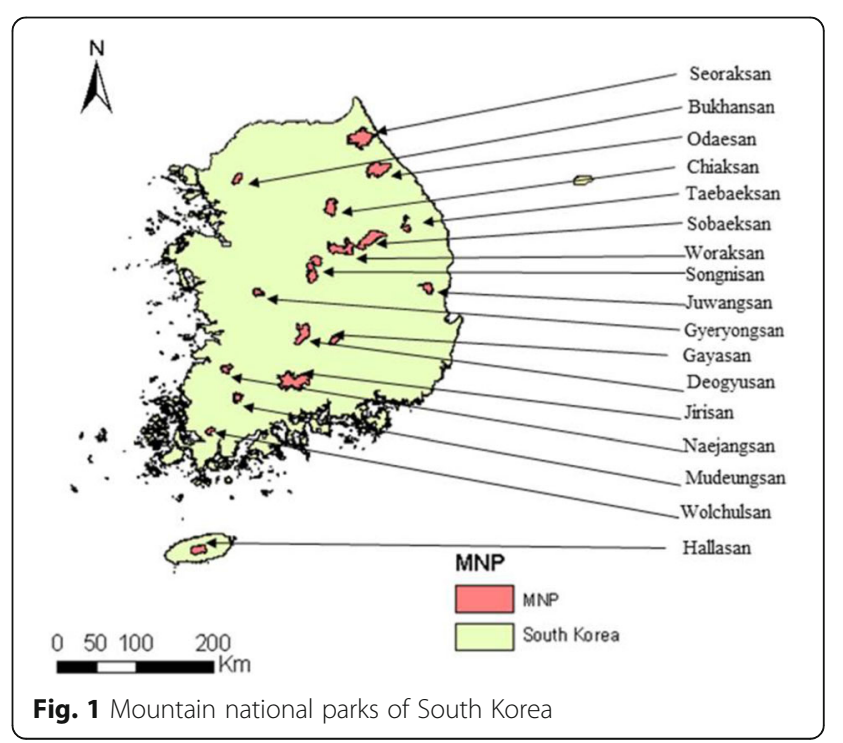


Table 1 List of mountain national parks of South Korea

\begin{tabular}{lllll}
\hline $\begin{array}{l}\text { Mountain } \\
\text { national park }\end{array}$ & Area $\left(\mathrm{km}^{2}\right)$ & Altitude $(\mathrm{m})$ & Latitude & Longitude \\
\hline Chiaksan & 175.66 & 1288 & $37.23^{\circ}-37.43^{\circ}$ & $127.99^{\circ}-128.14^{\circ}$ \\
Sobaeksan & 322.01 & 1439 & $37.06^{\circ}-36.84^{\circ}$ & $128.35^{\circ}-128.71^{\circ}$ \\
Mudeungsan & 75.42 & 1187 & $35.06^{\circ}-35.19^{\circ}$ & $126.06^{\circ}-126.93^{\circ}$ \\
Bukhansan & 76.92 & 837 & $37.60^{\circ}-37.74^{\circ}$ & $126.93^{\circ}-127.04^{\circ}$ \\
Deogyusan & 229.43 & 1614 & $35.74^{\circ}-35.99^{\circ}$ & $127.64^{\circ}-126.82^{\circ}$ \\
Gayasan & 76.25 & 1433 & $35.75^{\circ}-35.85^{\circ}$ & $128.04^{\circ}-128.17^{\circ}$ \\
Gyeryongsan & 65.33 & 845 & $36.30^{\circ}-36.39^{\circ}$ & $127.17^{\circ}-127.25^{\circ}$ \\
Hallasan & 153.38 & 1950 & $33.31^{\circ}-33.42^{\circ}$ & $126.46^{\circ}-126.63^{\circ}$ \\
Jirisan & 483.02 & 1915 & $35.21^{\circ}-35.44^{\circ}$ & $127.45^{\circ}-127.82^{\circ}$ \\
Juwangsan & 105.59 & 721 & $36.33^{\circ}-36.46^{\circ}$ & $129.08^{\circ}-129.24^{\circ}$ \\
Naejangsan & 80.70 & 763 & $35.41^{\circ}-35.52^{\circ}$ & $126.80^{\circ}-126.93^{\circ}$ \\
Odaesan & 326.34 & 1563 & $37.68^{\circ}-37.86^{\circ}$ & $128.48^{\circ}-128.76^{\circ}$ \\
Seoraksan & 398.23 & 1708 & $38.01^{\circ}-38.22^{\circ}$ & $128.25^{\circ}-128.59^{\circ}$ \\
Songnisan & 274.76 & 1058 & $36.78^{\circ}-36.47^{\circ}$ & $127.78^{\circ}-127.96^{\circ}$ \\
Wolchulsan & 56.22 & 812.7 & $34.69^{\circ}-34.78^{\circ}$ & $126.62^{\circ}-126.73^{\circ}$ \\
Taebaeksan & 70.05 & 1566.7 & $37.04^{\circ}-37.24^{\circ}$ & $128.87^{\circ}-128.99^{\circ}$ \\
Woraksan & 287.57 & 1097 & $36.98^{\circ}-36.78^{\circ}$ & $128.02^{\circ}-128.33^{\circ}$ \\
\hline Atiude & & &
\end{tabular}

Altitude indicates the elevation of highest peak of mountain national park

zone of South Korea. In each species, the minimum species presence points were maintained 10 for getting accurate model performance. Altogether, 723 species presence points (Fig. 2) of 14 subalpine plant species were used in this study, and random points were determined from the raster map of South Korea using Arc GIS 10.3 (Esri, Redlands, CA, USA).

\section{Climate data}

We considered 19 bioclimatic variables (Additional file 1) to be important for the distribution of subalpine plant species and obtained monthly minimum temperature, maximum temperature, and precipitation data for estimating the current and future climate of South Korea from the Korea Meteorological Administration (KMA). We used the HedGEM3-RA global circulation model to predict the future climate change scenarios RCP 4.5 and RCP 8.5 through Package Dismo in R (Robert et al. 2017). The current climate conditions were estimated by averaging the data from 1950 to 2000, and the future climate conditions in 2050 were estimated from the period of 2046 to 2055. Similarly, the future climate conditions in 2070 were estimated by averaging data from the period of 2066 to 2075. In all climatic data, the spatial resolution was $0.01^{\circ}(36 \mathrm{~s})$ and approximately $1 \mathrm{~km}^{2}$.

\section{Model development}

Pearson's correlation between the pairs of predictors was used to select the bioclimatic variables and eliminate the weaker predictors, which showed a high correlation $(>0.70)$ with another variable. We used the MaxEnt package 1.3.3 in R software (https://cran.r-project.org/web/packages/maxent) to predict the current and future distribution of subalpine plant species in the MNP of South Korea. During modeling, $75 \%$ of the data was used in model calibration, and $25 \%$ of the data was used to test the predictive ability of the model. We performed 10 replications and maintained cross-validation in the replicate runs to guarantee the accuracy of the model.

\section{Model evaluation and validation}

The goodness of fit of the model was evaluated with the area under the curve (AUC) values of the receiver operating characteristics (ROC) curves (Pearsons 2010) and the true skill statistic (TSS). The test data points were used to calculate the AUC value and TSS. The AUC was acting as a threshold-independent technique to differentiate presence from absence to evaluate model performance (Thuiller et al. 2005). The AUC values vary from 0 to 1 . A higher value of AUC suggests superiority. The model performance was categorized as poor (0.5-0.6), fair (0.6-0.7), good (0.7-0.8), very good (0.8-0.9), and excellent (0.9-1) (Swets 1988). The TSS is threshold dependent and measures the model performance by assessing the classification accuracy after choosing a threshold value and ranges between -1 and +1 . This shows an account of both omission and commission errors. The values towards -1 signify agreement no

Table $\mathbf{2}$ List of subalpine species used for species richness modeling

\begin{tabular}{|c|c|c|c|c|c|}
\hline Species name & $\begin{array}{l}\text { Plant } \\
\text { type }\end{array}$ & $\begin{array}{l}\text { Distribution } \\
\text { range }\end{array}$ & $\begin{array}{l}\text { Presence } \\
\text { point }\end{array}$ & $\begin{array}{l}\text { AUC } \\
\text { value }\end{array}$ & $\begin{array}{l}\text { TSS } \\
\text { value }\end{array}$ \\
\hline Abies koreana & Tree & Narrow & 37 & 0.99 & 0.90 \\
\hline Abies nephrolepis & Tree & Narrow & 31 & 0.98 & 0.84 \\
\hline Thuja koraiensis & Shrub & Narrow & 14 & 0.99 & 0.97 \\
\hline Oplopanax elatus & Shrub & Narrow & 18 & 0.99 & 0.95 \\
\hline $\begin{array}{l}\text { Acer } \\
\text { mandshuricum }\end{array}$ & Tree & Middle & 42 & 0.97 & 0.88 \\
\hline Acer tegmentosum & Tree & Middle & 55 & 0.96 & 0.85 \\
\hline Acer ukurunduense & Shrub & Middle & 59 & 0.97 & 0.89 \\
\hline Lilium cernuum & Herb & Middle & 29 & 0.93 & 0.78 \\
\hline $\begin{array}{l}\text { Saussurea } \\
\text { macrolepis }\end{array}$ & Herb & Wide & 73 & 0.92 & 0.75 \\
\hline $\begin{array}{l}\text { Gentiana triflora } f \text {. } \\
\text { japonica }\end{array}$ & Herb & Wide & 54 & 0.93 & 0.75 \\
\hline Abies holophylla & Tree & Wide & 66 & 0.89 & 0.72 \\
\hline Taxus cuspidata & Tree & Wide & 64 & 0.91 & 0.70 \\
\hline Lonicera subsessilis & Shrub & Wide & 141 & 0.92 & 0.72 \\
\hline Carex okamotoi & Grass & Wide & 40 & 0.89 & 0.75 \\
\hline
\end{tabular}

AUC area under the curve, TSS true skill statistic 


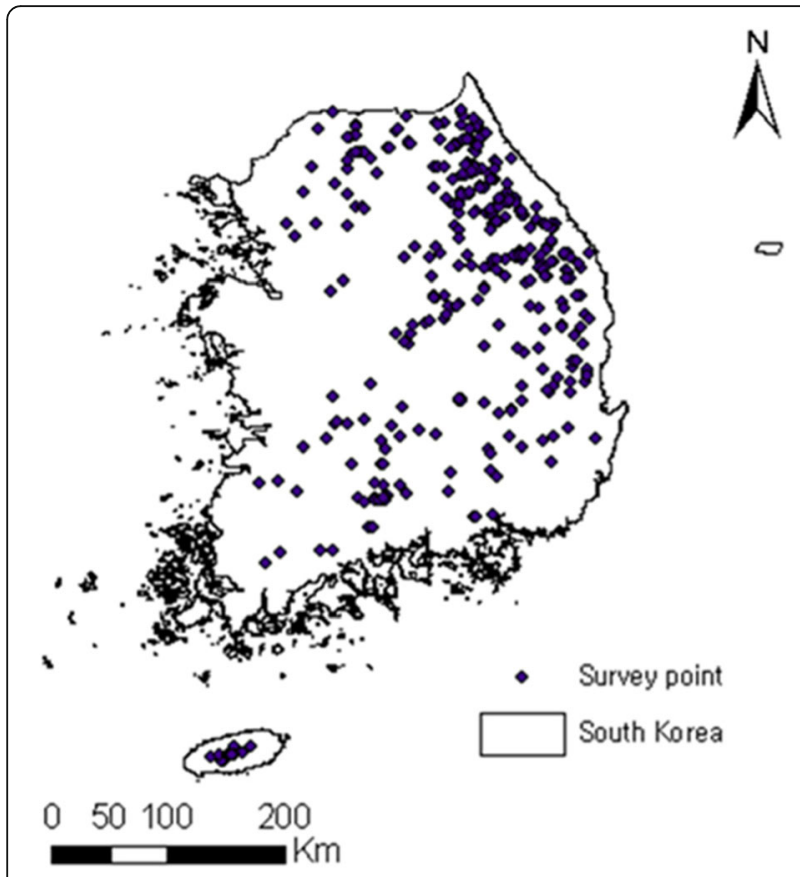

Fig. 2 Sampling sites of subalpine plant species in South Korea

better than random, and the values towards +1 indicate an agreement between observation and prediction (Allouche et al. 2006).

\section{Dispersal analysis}

The degree of dispersal was determined with probabilities according to distances by applying a negative exponential dispersal kernel (see Eq. 1) based on the Euclidean distance $d$ of each grid cell to the closest known species location (Portnoy and Willson 1993).

$$
D_{\theta}=e^{(\theta d)} \text { for } \theta\{-0.005,-0.001,-0.0005\}
$$

where, $D_{\theta}$ is the dispersal probability by distance according to $\theta . \theta$ is the gradient of the negative exponential function, at which $0.005,0.001$, and 0.0005 were used, and $d$ is the dispersal distance. Here, the coefficient value $\theta=-0.005$ considered the lower bound approximates of seed dispersal of $1 \mathrm{~km}$ per year. The coefficient value $\theta=-0.001$ denotes a seed dispersal kernel by an animal with seed dispersal of up to $5 \mathrm{~km}$ per year (Vellend et al. 2003). The coefficient value $\theta=-0.0005$ denotes the probability of long distance dispersal (LDD), having seed dispersal of up to $10 \mathrm{~km}$ per year (Crossman et al. 2012). In this equation, the negative exponential function assigns a higher dispersal potential score to the region close to the known species locations than to farther away (Crossman et al. 2012). The other parameters, such as the initial species distribution, habitat suitability map, barriers to dispersal, propagule production potential, minimum and maximum distances for LDD, and number of environmental change and dispersal steps, were used in the Migclim model as suggested by Engler et al. (2012). The potential dispersal of each species was estimated for the years 2050 and 2070. The Migclim output raster files were reclassified into suitable and unsuitable habitats according to the status of the raster cells that were occupied or unoccupied or colonized, non-colonized, or decolonized at the end of the simulation (Engler 2012).

\section{Species richness calculation}

The raster of each subalpine plant species was summed to determine the current and potential species richness map. The shape file of the 17 MNPs of South Korea was overlaid on the species richness maps, and extraction of the multi values to points was carried out using the spatial analyst tool of ArcGIS 10.3 (Esri, Redlands, CA, USA). The average and maximum species richness in each MNP were determined through the extracted richness at different points of the MNP.

\section{Results and discussion}

\section{Bioclimatic variable selection}

Pearson's correlation analysis among the 19 bioclimatic variables (Additional file 1) determined six variables: annual mean temperature (Bio1), mean diurnal temperature range (Bio2), isothermality (Bio3), annual precipitation (Bio12), precipitation of the wettest month (Bio13), and precipitation of the driest month (Bio14). These variables have weak correlations, but they have high correlations $(r<0.99)$ with other climatic variables (Additional file 2). Therefore, these six variables were selected for MaxEnt modeling. In this study, we used only bioclimatic variable for modeling at the national scale in macro level. It is a part of ongoing research; therefore, other variables such as soil characteristics like soil temperature, soil moisture, and nutrients will be used in our next study "microhabitat analysis in subalpine ecosystem."

\section{Model evaluation and validation}

Altogether, 14 subalpine plant species (Table 2) were used in this study, and an independent species distribution model was established for the current and future distribution of each species. The model performance of the species distribution model was determined by measuring the AUC value and TSS value of the final ensemble results. The measurement of the performance of SDM should not be influenced by the size of the data (prevalence) but should integrate both omission error (sensitivity) and commission error 
(specificity) (Allouche et al. 2006). The AUC does not depend on the prevalence, but it is sometimes criticized because it equally weights commission and omission errors and ignores the actual probability values (Lobo et al. 2008). In particular, the AUC value increases while expanding the geographical extent of rare species outside of the present range (Lobo et al. 2008). Therefore, we used both the AUC and TSS values to improve the model performance. In this study, we determined the AUC and TSS values for checking the model performance of all studied species. The mean AUC value of the 14 species was $0.94(0.89-0.99)$, and the mean TSS value was $0.81(0.70-0.90)$ (Table 2). The mean value of AUC signifies that the model performance was excellent; therefore, it leads to outstanding prediction results (Swets 1988). Similarly, the mean value of TSS indicates that there was an agreement between the observation and prediction of the model (Allouche et al. 2006). We determined high AUC values of some narrow ranged species, such as Thuja koraiensis (0.99), Abies koreana, and Oplopanax elatus (0.98) (Table 2). We were concerned about the over estimation of the AUC due to the restricted geographical distribution as suggested by Lobo et al. (2008), but the value of TSS revealed that the model performance was evaluated correctly.

\section{Contribution of the bioclimatic variables in the model}

In total, six bioclimatic variables contributed in the predictive model for the studied species (Table 3). The bioclimatic variable with the highest contribution to the model was annual mean temperature (Bio1) in all studied species except A. koreana. Bio1 contributed 47.7-96.5\% in 13 of the studied species, but in A. koreana, the annual precipitation (Bio12) had the highest contribution (83.5\%). This indicates that the annual mean temperature was a dominant driving factor for the subalpine species, and precipitation was a minor factor in a range of the subalpine species. However, in $A$. koreana, annual precipitation was the most powerful controlling factor for its natural habitat. We checked the mean annual precipitation in all MNPs and found high precipitation in Hallasan $(2039 \mathrm{~mm})$, Jirisan (1561 mm), Gayasan (1464 mm), and Deogyusan $(1448 \mathrm{~mm})$ compared to other MNPs $(1200 \mathrm{~mm})$ (Source: KMA). These four MNPs only have the natural habitat of $A$. koreana. Further study is required in microscale to understand annual precipitation's ecological role in A. koreana. For subalpine species, altitude could be a controlling factor, but it has high correlation with mean annual temperature. Thus, we only used bioclimatic variables to study the species distribution model.

\section{Species richness}

The potential species richness of subalpine plant species under the current climatic conditions is documented in Fig. 3. The MNPs located in the northeastern region, namely, Odaesan, Seoraksan, and Taebaeksan, showed pronounced species richness. The average species richness was estimated to be 11.20 to 11.26 , and the maximum species richness was 14 (Table 4). A cold climate due to the latitudinal effect and high elevation could be the possible reason for high species richness (Golicher et al. 2012; Koo et al. 2015). However, the MNPs of the southern region (Mudeungsan, Naejangsan, and Wolchulsan) and central region (Gyeryongsan and Songnisan) have relatively low species richness (average, 2.073.45 and maximum, 8.0-12.0) (Table 4). These MNPs represent areas with relatively low latitudes and more humid and hotter climates than the northeastern region. Therefore, these MNPs do not have the habitat of some subalpine species (e.g., A. koreana), which are sensitive to heat stress and heat-associated drought stress and strongly prefer to exist in low temperature, low radiation, and close to a water source, as reported by Koo et al. (2017).

Similarly, the MNPs Bukhansan, Chiaksan, Jirisan, Deogyusan, Gayasan, and Hallasan have a wide range of average species richness (5.24-8.96) but almost similar maximum species richness (13-14). These results indicate that specific and limited regions, such as mountain ranges with high elevations, are currently suitable for the all-studied subalpine species. This study also determined the average and maximum species richness of the entire region of South Korea, which estimated the equal maximum species richness in the MNPs, but the

Table 3 Estimating the contribution (\%) of bioclimatic variable in models

\begin{tabular}{lllllll}
\hline Name of species & Bio1 & Bio2 & Bio3 & Bio12 & Bio13 & Bio14 \\
\hline Abies koreana & 6.6 & 0.5 & 0 & 83.5 & 4.1 & 5.3 \\
Abies nephrolepis & 89.4 & 2.7 & 1.9 & 0.4 & 1.9 & 3.7 \\
Thuja koraiensis & 89.2 & 7.9 & 2.8 & 0 & 0 & 0.2 \\
Oplopanax elatus & 78.9 & 2.7 & 2.4 & 0.2 & 10.9 & 4.9 \\
Acer mandshuricum & 92.9 & 0.7 & 2.1 & 0.3 & 2.1 & 0 \\
Acer tegmentosum & 96.5 & 0.2 & 0.3 & 0 & 2.5 & 0.4 \\
Acer ukurunduense & 94.5 & 2.0 & 3.0 & 0 & 0.4 & 0.1 \\
Lilium cernuum & 75.9 & 8.5 & 5.0 & 1.0 & 3.4 & 6.4 \\
Saussurea macrolepis & 71.0 & 10.8 & 2.6 & 10.8 & 6.1 & 5.2 \\
Gentiana triflora f. japonica & 91.0 & 3.2 & 3.0 & 1.2 & 1.6 & 0.1 \\
Abies holophylla & 80.7 & 2.9 & 2.2 & 7.8 & 6.3 & 0.2 \\
Taxus cuspidata & 72.4 & 2.2 & 0.1 & 2.2 & 1.8 & 1.2 \\
Lonicera subsessilis & 75.0 & 3.1 & 3.9 & 3.1 & 6.4 & 11 \\
Carex okamotoi & 47.7 & 19.8 & 9.2 & 14.1 & 3.0 & 6.2 \\
\hline
\end{tabular}


average species richness differed on a large scale, showing a large proportion of subalpine ecosystems protected inside the MNPs of South Korea.

\section{Impact of climate change on species richness}

Climate change is predicted to increase the temperature over South Korea in the range of $0.63{ }^{\circ} \mathrm{C}$ per decade up to year 2100 (Ministry of Environment 2018). Under this temperature increase, the suitable habitat of all subalpine species will decline. Therefore, the potential species richness of the subalpine species in the MNPs of South Korea was predicted to decrease by 2050 and 2070 under the climate change scenarios RCP 4.5 (Table 4 and Fig. 4) and RCP 8.5 (Table 5 and Fig. 5).

Under RCP 4.5, the average and maximum species richness in the MNPs would be reduced in a range of $15.38-94.02 \%$ by 2050 and would be reduced in a range of $21.42-96.64 \%$ by 2070 at dispersal conditions of $5 \mathrm{~km}$ per year. The MNPs existing in the central (Songnisan and Gyeryongsan), eastern (Juwangsan), and southern regions (Mudeungsan, Wolchulsan, Hallasan, and Jirisan) have predicted average species richness reductions over $60 \%$ by 2050 and over $70 \%$ by 2070 . However, the MNPs situated in the north (Bukhansan) and northeastern regions (Odaesan, Seoraksan, Chiaksan, and Taebaeksan) have forecasted decreases in species richness of up to $29.46 \%$ by 2050 and up to $54 \%$ by 2070 .

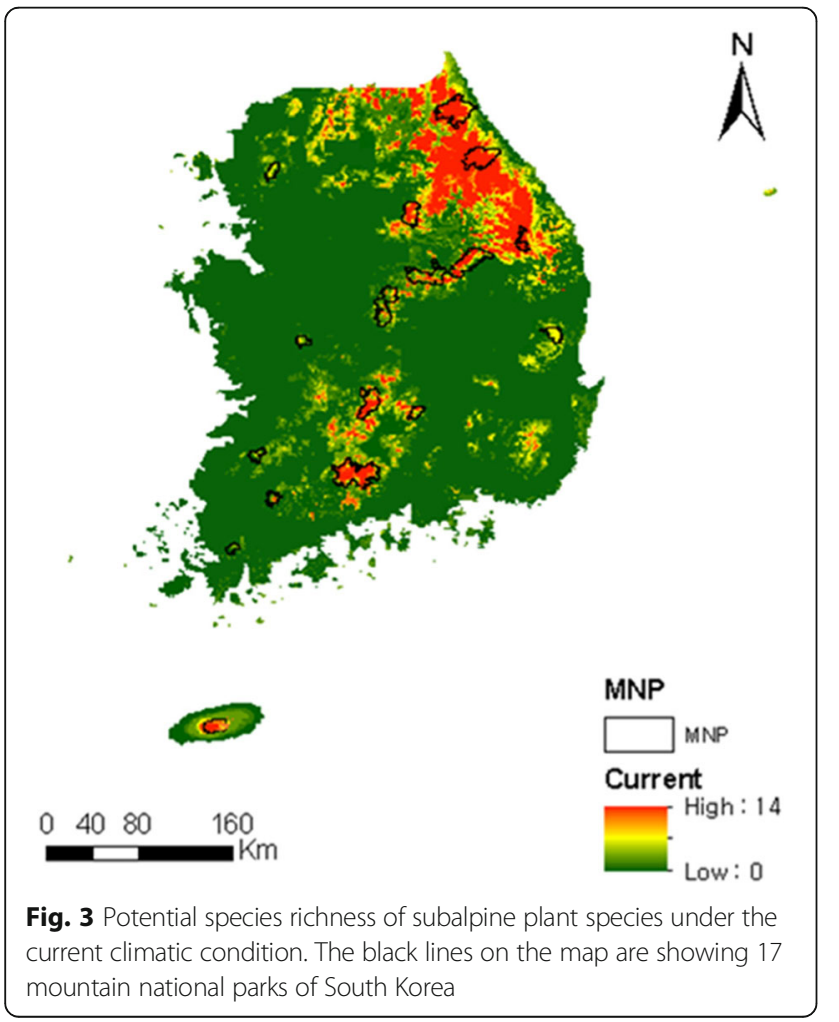

Under RCP 8.5, further reduction of the species richness is predicted in all MNPs, which would happen as the temperature continues to increase. Therefore, the average and maximum species richness reduction in all MNPs would be higher by 2050 and 2070 than under RCP 4.5 at dispersal conditions of $5 \mathrm{~km}$ per year. The average and maximum species richness in MNP was predicted to decrease by $15.38-97.9 \%$ by 2050 and $23.07-100 \%$ by 2070 . Similar to RCP 4.5 , the MNPs of the southern central and eastern regions (59.47-100\%) will have higher rates of average species reduction compared to the northern and northeastern regions (25.19-64.28\%). Some MNPs, such as Juwangsan, Gyeryongsan, Mudeungsan, Songnisan, and Wolchulsan, have serious climate change impacts predicted in subalpine species, at which the average and maximum species richness would be reduced by over $80 \%$ by 2050 and over $90 \%$ by 2070 . Similar predictions have made by Koo et al. (2015) on cold evergreen plants in the southern region of South Korea, except for Jeju Island. As with the MNPs, the average species richness in an entire area of South Korea was predicted to decrease by 2050 and 2070 under both climate change scenarios, but the maximum species richness will remain almost constant.

Our results revealed that the species richness of subalpine species will decrease continuously by 2050 and 2070 under both climate change scenarios. The rate of reduction of species richness was relatively high in the MNPs located below $36.84^{\circ}$ latitude except Jirisan and Hallasan, and their highest peak ranged from 721 to $1187 \mathrm{~m}$. However, MNPs existing between $37.04^{\circ}$ and $38.22^{\circ}$ latitude have the maximum elevation of 1288 $1708 \mathrm{~m}$. This shows that the subalpine species existing in the MNPs of the northern and northeastern were favored by high altitude and high elevation.

Of the various bioclimatic variables, temperature is a main factor limiting subalpine plant distribution. However, precipitation also determines the factor for some species (e.g., A. koreana), but warming temperature caused several negative ecological effects on the subalpine species. These effects included (1) reducing the growth period by increasing the winter dormancy period (Myking and Heide 1995; Heide 2003), (2) damage of buds released from dormancy under warmer temperature due to the late season frost, (3) winter time drought damage combined with frozen soil (Sevanto et al. 2006), (4) increased high temperatureinduced photo inhibition during summer (Dumais and Prévost 2007), and (5) tissue damage and mortality of embryos (Boden et al. 2010; Rixen et al. 2012). The presence of plant species in the subalpine region may exhibit morphological and physiological adaptation for survival in stress-limiting environments. However, many 
Table 4 Prediction of potential species richness of subalpine species at RCP 4.5

\begin{tabular}{|c|c|c|c|c|c|c|c|c|c|c|c|c|c|c|c|c|c|c|}
\hline \multirow{3}{*}{$\begin{array}{l}\text { Mountain } \\
\text { national } \\
\text { parks }\end{array}$} & \multirow{2}{*}{\multicolumn{2}{|c|}{ Current }} & \multicolumn{8}{|l|}{2050} & \multicolumn{8}{|l|}{2070} \\
\hline & & & \multicolumn{2}{|c|}{$1 \mathrm{~km} /$ year } & \multicolumn{2}{|c|}{$5 \mathrm{~km} /$ year } & \multicolumn{2}{|c|}{10 km/year } & \multicolumn{2}{|c|}{ Unlimited } & \multicolumn{2}{|c|}{1 km/year } & \multicolumn{2}{|c|}{$5 \mathrm{~km} /$ year } & \multicolumn{2}{|c|}{10 km/year } & \multicolumn{2}{|c|}{ Unlimited } \\
\hline & Avg & Max & Avg & Max & Avg & Max & Avg & Max & Avg & $\operatorname{Max}$ & Avg & Max & Avg & Max & Avg & Max & Avg & Max \\
\hline Chiaksan & 7.86 & 13 & 5.63 & 10 & 5.85 & 10 & 5.85 & 10 & 5.98 & 11 & 4.03 & 6 & 4.09 & 7 & 4.91 & 7 & 5.02 & 9 \\
\hline Sobaeksan & 5.60 & 13 & 1.98 & 8 & 2.60 & 9 & 2.88 & 9 & 2.98 & 9 & 1.16 & 6 & 1.82 & 6 & 1.94 & 6 & 2.22 & 9 \\
\hline Mudeungsan & 2.07 & 9 & 0.60 & 4 & 0.81 & 4 & 0.81 & 4 & 0.96 & 4 & 0.60 & 3 & 0.62 & 3 & 0.65 & 3 & 0.85 & 4 \\
\hline Bukhansan & 7.55 & 13 & 4.43 & 13 & 5.50 & 13 & 5.50 & 13 & 5.95 & 13 & 2.99 & 8 & 3.43 & 9 & 4.09 & 11 & 5.08 & 13 \\
\hline Deogyusan & 7.83 & 13 & 3.81 & 11 & 4.79 & 11 & 4.82 & 11 & 4.96 & 12 & 2.34 & 6 & 3.17 & 6 & 3.29 & 6 & 4.09 & 11 \\
\hline Gayasan & 8.34 & 13 & 4.69 & 11 & 6.05 & 11 & 6.09 & 11 & 6.15 & 11 & 3.57 & 6 & 4.42 & 6 & 4.42 & 6 & 5.39 & 10 \\
\hline Gyeryongsan & 2.78 & 8 & 0.16 & 1 & 0.53 & 1 & 0.53 & 1 & 0.84 & 4 & 0.01 & 1 & 0.16 & 1 & 0.31 & 3 & 0.32 & 3 \\
\hline Hallasan & 8.76 & 14 & 3.02 & 4 & 3.01 & 4 & 3.02 & 4 & 5.02 & 6 & 2.98 & 3 & 3.21 & 4 & 3.35 & 4 & 3.58 & 5 \\
\hline Jirisan & 8.96 & 14 & 3.04 & 6 & 3.31 & 6 & 3.32 & 6 & 3.38 & 6 & 2.76 & 4 & 2.85 & 4 & 2.85 & 4 & 2.88 & 5 \\
\hline Juwangsan & 3.45 & 8 & 0.10 & 1 & 0.58 & 1 & 0.58 & 1 & 0.76 & 4 & 0.08 & 1 & 0.10 & 1 & 0.18 & 3 & 0.20 & 3 \\
\hline Naejangsan & 2.12 & 12 & 1.00 & 4 & 1.02 & 5 & 1.57 & 5 & 1.93 & 5 & 1.31 & 3 & 1.43 & 3 & 1.43 & 3 & 1.43 & 3 \\
\hline Odaesan & 11.26 & 14 & 8.23 & 14 & 9.23 & 14 & 9.24 & 14 & 9.51 & 14 & 3.40 & 8 & 5.31 & 11 & 6.98 & 11 & 8.22 & 11 \\
\hline Seoraksan & 11.26 & 14 & 7.79 & 14 & 9.23 & 14 & 8.40 & 14 & 9.51 & 14 & 4.30 & 9 & 5.31 & 9 & 6.99 & 13 & 8.22 & 14 \\
\hline Songnisan & 2.68 & 9 & 0.16 & 3 & 0.16 & 3 & 0.17 & 3 & 0.21 & 4 & 1.01 & 2 & 1.05 & 3 & 1.07 & 3 & 1.98 & 5 \\
\hline Wolchulsan & 2.69 & 9 & 0.07 & 1 & 0.17 & 3 & 1.04 & 3 & 1.21 & 4 & 1.02 & 1 & 1.06 & 3 & 1.09 & 3 & 1.86 & 5 \\
\hline Taebaeksan & 11.20 & 14 & 7.50 & 12 & 7.90 & 12 & 7.95 & 12 & 8.20 & 12 & 6.55 & 8 & 6.95 & 8 & 6.95 & 8 & 7.13 & 11 \\
\hline Woraksan & 5.24 & 13 & 1.67 & 6 & 2.20 & 6 & 2.47 & 7 & 2.57 & 7 & 0.69 & 4 & 1.12 & 5 & 1.31 & 5 & 1.80 & 7 \\
\hline South Korea & 1.80 & 14 & 0.59 & 14 & 1.07 & 14 & 1.14 & 14 & 1.36 & 14 & 0.36 & 10 & 0.69 & 13 & 0.75 & 13 & 0.89 & 14 \\
\hline
\end{tabular}

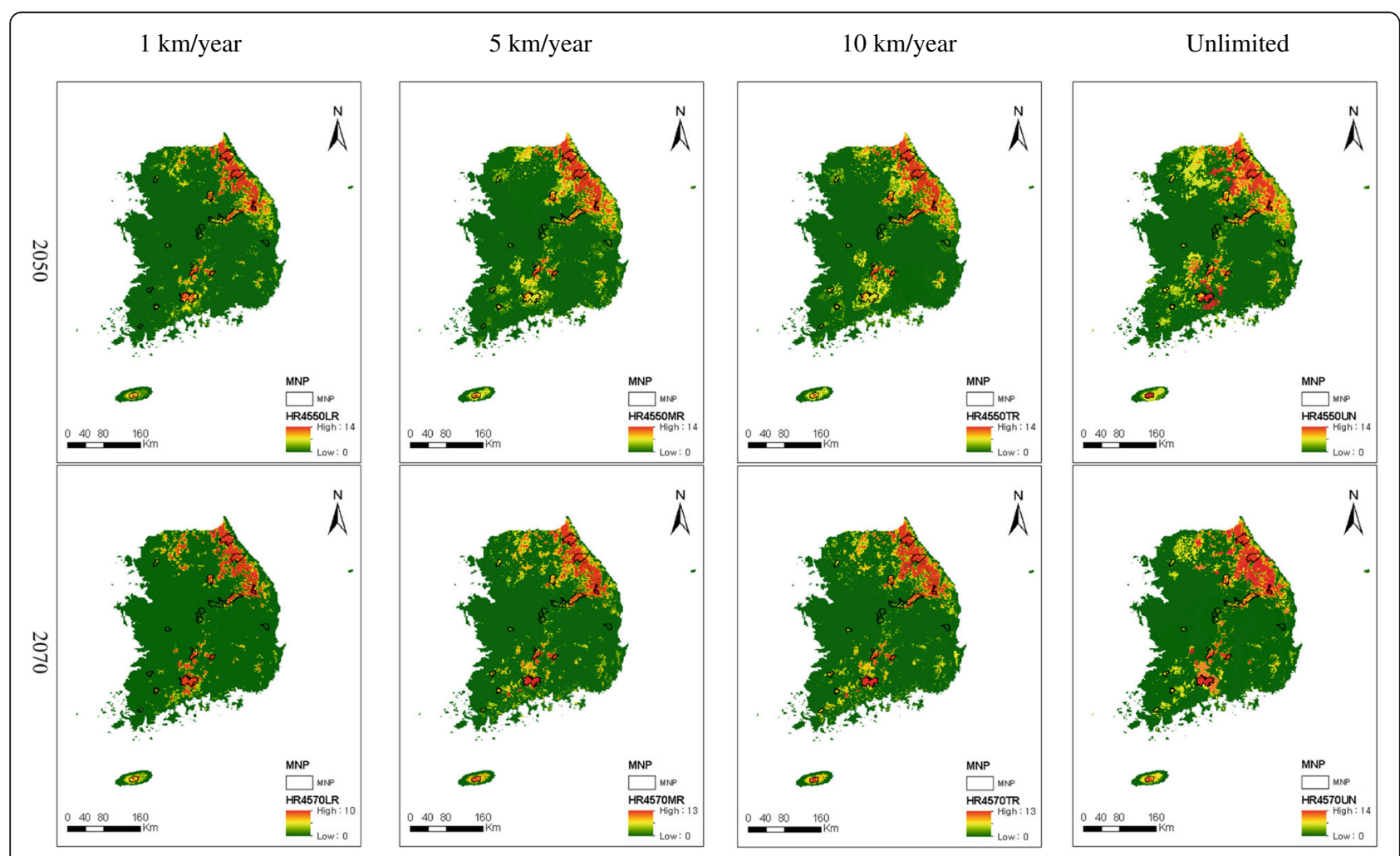

Fig. 4 Potential species richness of subalpine plant species under the climate change scenario RCP 4.5. The black lines on the map are showing 17 mountain national parks of South Korea 
Table 5 Prediction of potential species richness of subalpine species at RCP 8.5

\begin{tabular}{|c|c|c|c|c|c|c|c|c|c|c|c|c|c|c|c|c|c|c|}
\hline \multirow{3}{*}{$\begin{array}{l}\text { Mountain } \\
\text { national } \\
\text { parks }\end{array}$} & \multirow{2}{*}{\multicolumn{2}{|c|}{ Current }} & \multicolumn{8}{|l|}{2050} & \multicolumn{8}{|l|}{2070} \\
\hline & & & \multicolumn{2}{|c|}{$1 \mathrm{~km} /$ year } & \multicolumn{2}{|c|}{$5 \mathrm{~km} /$ year } & \multicolumn{2}{|c|}{10 km/year } & \multicolumn{2}{|c|}{ Unlimited } & \multicolumn{2}{|c|}{$1 \mathrm{~km} /$ year } & \multicolumn{2}{|c|}{$5 \mathrm{~km} /$ year } & \multicolumn{2}{|c|}{10 km/year } & \multicolumn{2}{|c|}{ Unlimited } \\
\hline & Avg & Max & Avg & Max & Avg & Max & Avg & Max & Avg & $\operatorname{Max}$ & Avg & Max & Avg & Max & Avg & Max & Avg & Max \\
\hline Chiaksan & 7.86 & 13 & 5.40 & 9 & 5.84 & 9 & 5.84 & 9 & 5.93 & 11 & 5.71 & 6 & 5.88 & 6 & 5.99 & 6 & 6.05 & 9 \\
\hline Sobaeksan & 5.60 & 13 & 1.28 & 7 & 1.82 & 8 & 1.84 & 8 & 1.90 & 8 & 1.02 & 5 & 1.27 & 7 & 1.27 & 7 & 1.32 & 7 \\
\hline Mudeungsan & 2.07 & 9 & 0.41 & 3 & 0.44 & 3 & 0.44 & 3 & 0.77 & 6 & 0.36 & 3 & 0.44 & 3 & 0.44 & 3 & 0.48 & 4 \\
\hline Bukhansan & 7.55 & 13 & 2.76 & 9 & 3.25 & 11 & 3.34 & 11 & 3.44 & 11 & 2.00 & 7 & 3.20 & 10 & 3.30 & 11 & 3.38 & 11 \\
\hline Deogyusan & 7.83 & 13 & 2.92 & 9 & 3.69 & 10 & 3.74 & 10 & 3.91 & 11 & 1.32 & 8 & 1.56 & 8 & 1.61 & 8 & 1.64 & 9 \\
\hline Gayasan & 8.34 & 13 & 4.09 & 8 & 4.89 & 9 & 4.92 & 9 & 5.14 & 9 & 2.07 & 5 & 2.46 & 6 & 2.54 & 6 & 2.57 & 6 \\
\hline Gyeryongsan & 2.78 & 8 & 0.06 & 1 & 0.11 & 1 & 0.11 & 1 & 0.13 & 2 & 0.00 & 0 & 0.00 & 0 & 0.00 & 0 & 0.00 & 0 \\
\hline Hallasan & 8.76 & 14 & 4.12 & 5 & 4.23 & 5 & 4.59 & 5 & 4.95 & 5 & 3.01 & 4 & 3.25 & 4 & 3.55 & 4 & 3.76 & 4 \\
\hline Jirisan & 8.96 & 14 & 2.75 & 6 & 2.97 & 6 & 3.04 & 6 & 3.11 & 8 & 2.62 & 3 & 2.82 & 3 & 2.82 & 3 & 2.85 & 3 \\
\hline Juwangsan & 3.45 & 8 & 0.04 & 1 & 0.07 & 1 & 0.07 & 1 & 0.08 & 2 & 0.00 & 0 & 0.00 & 0 & 0.00 & 0 & 0.00 & 0 \\
\hline Naejangsan & 2.12 & 12 & 0.27 & 3 & 0.49 & 4 & 0.53 & 4 & 0.56 & 4 & 0.31 & 3 & 0.47 & 3 & 0.47 & 3 & 0.51 & 3 \\
\hline Odaesan & 11.26 & 14 & 6.03 & 9 & 6.25 & 13 & 6.30 & 13 & 6.87 & 14 & 4.69 & 8 & 4.87 & 13 & 5.17 & 13 & 5.30 & 14 \\
\hline Seoraksan & 11.26 & 14 & 6.06 & 13 & 6.33 & 11 & 6.40 & 13 & 6.89 & 14 & 4.85 & 11 & 4.87 & 11 & 5.44 & 12 & 5.53 & 13 \\
\hline Songnisan & 2.68 & 9 & 0.14 & 3 & 0.45 & 3 & 0.46 & 3 & 0.47 & 3 & 0.11 & 2 & 0.12 & 3 & 0.12 & 3 & 0.22 & 3 \\
\hline Wolchulsan & 2.69 & 9 & 0.18 & 1 & 0.45 & 3 & 0.73 & 3 & 0.77 & 3 & 0.20 & 1 & 0.12 & 3 & 0.18 & 3 & 0.25 & 3 \\
\hline Taebaeksan & 11.20 & 14 & 4.81 & 10 & 5.79 & 11 & 5.80 & 11 & 5.86 & 11 & 2.73 & 8 & 4.00 & 9 & 4.00 & 9 & 4.05 & 9 \\
\hline Woraksan & 5.24 & 13 & 1.00 & 5 & 1.43 & 5 & 1.46 & 5 & 1.53 & 5 & 0.86 & 4 & 1.04 & 4 & 1.04 & 4 & 1.08 & 4 \\
\hline South Korea & 1.80 & 14 & 0.45 & 14 & 0.67 & 14 & 0.69 & 14 & 0.77 & 14 & 0.29 & 12 & 0.54 & 13 & 0.57 & 13 & 0.69 & 14 \\
\hline
\end{tabular}

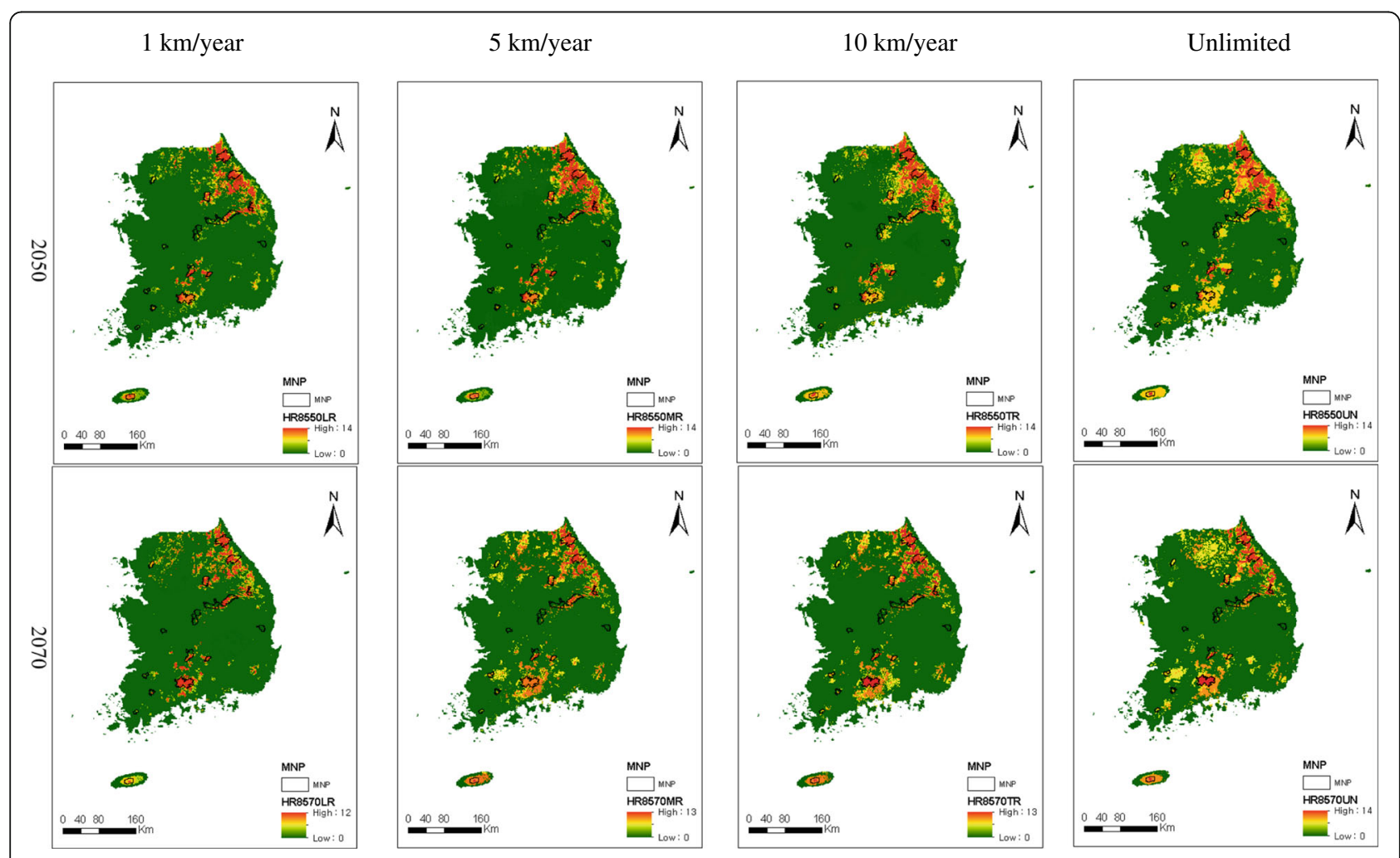

Fig. 5 Potential species richness of subalpine plant species under the climate change scenario RCP 8.5. The black lines on the map are showing 17 mountain national parks of South Korea 
of these adaptations depend heavily on the air temperature (Buytaert et al. 2011). Therefore, climate change ceased all of these processes and was unable to track new climatic niches, resulting in species extinction.

The Baekdu Daegan Mountain region (Miller and Hyun 2009) in Ganwon Province (northeastern region), Kyungsangnam province (southern region), and Jeollabuk province (Southern west region) have many high mountains, which are not included inside the MNPS have predicted high species richness of subalpine species (Figs. 3, 4, and 5). Therefore, identification of new habitat of subalpine species and designating them under protected areas are required for their conservation.

Very little literature is available on subalpine plant species in South Korea, and there is no uniformity about the distribution range. Several inconsistencies exist for these species, which have a wide range in distribution and are available below $500 \mathrm{~m}$ ASL. Therefore, we selected presence data only from natural habitats. Properly selecting presence data increases the accuracy of model predictability, which will provide better information for the formulation of conservation strategies. Thus, sufficient information about the distribution range, dispersal mechanism, acclimation capacity, and interaction with coexisting species are needed for each subalpine species at multiple spatial scales. In addition, model uncertainty (Hartley et al. 2006) and limitations of the measurement system, such as inadequate sample size, observation error, bias in sampling, and data collection, could affect the predictions (Higgins et al. 2003).

\section{Conclusions}

This study predicted potential species richness of subalpine plant species in MNPs of South Korea under current and future climate change scenarios RCP 4.5 and RCP 8.5. Currently, the MNPs located in the northeastern region of Odaesan, Seoraksan, and Taebaeksan showed high species richness compared to the MNPs in the southern and central regions (Mudeungsan, Naejangsan, Wolchulsan, Gyeryongsan, and Songnisan). In the future, the average richness would be reduced in all MNPs of South Korea. However, in contrast to the MNPs of the northern and northeastern regions, the rate of reduction would be relatively high in the MNPs existing in the eastern, central, and southern regions indicating the impact of climate change would be high in subalpine species occurred in low latitude. This study suggests it is necessary to minimize greenhouse gas emission, but it is also essential to apply other preventive measures such as protection of potential habitat of subalpine species, plantation, and re-seeding of subalpine species, control of invasive species, prevent from forest fire, and restoration of locally extinct species in order to reduce the declining of subalpine species. Our study provides valuable information about the current, and future distribution, and species richness of subalpine species, which could be significant to the government and conservation agency for deciding conservation strategies and management plan to protect subalpine species.

\section{Additional files}

Additional file 1: List of bioclimatic variables. (DOCX $16 \mathrm{~kb}$ )

Additional file 2: Spearman's correlation for variable selection. (DOCX 15 kb)

\section{Funding}

This study was funded by the "Climate Change Response Technology Project" of the Ministry of Environment, the Republic of Korea (Project No.: 2014001310009). Therefore, authors are grateful to the project for providing the research fund.

\section{Availability of data and materials \\ Not applicable}

\section{Authors' contributions}

PA analyzed the data, prepared the results, and wrote the manuscript. M-SS and J-YJ analyzed the data. HWK helped to draft the manuscript. SH participated in the design of the study, and CS designed the study and co-ordinate in overall research. All authors read and approved the final manuscript.

Ethics approval and consent to participate

Not applicable

\section{Consent for publication}

Not applicable

\section{Competing interests}

The authors declare that they have no competing interests.

\section{Publisher's Note}

Springer Nature remains neutral with regard to jurisdictional claims in published maps and institutional affiliations.

Received: 8 October 2018 Accepted: 30 November 2018

Published online: 27 December 2018

\section{References}

Allouche O, Tsoar A, Kadmon R. Assessing the accuracy of species distribution models: prevalence, kappa and the true skill statistic (TSS): assessing the accuracy of distribution models. J Appl Ecol. 2006;43:1223-32.

Boden S, Pyttel P, Eastaugh C. Impacts of climate change on the establishment, distribution, growth and mortality of Swiss stone pine (Pinus cembra L.). iForest - biogeosciences and Forestry. 2010;3:82-5.

Buytaert W, Cuesta-Camacho F, Tobón C. Potential impacts of climate change on the environmental services of humid tropical alpine regions. Glob Ecol Biogeogr. 2011;20:19-33.

Crossman ND, Bryan BA, Summers DM. Identifying priority areas for reducing species vulnerability to climate change: priorities for reducing species vulnerability to climate change. Divers Distrib. 2012;18:60-72.

Díaz S, Demissew S, Carabias J, et al. The IPBES conceptual frameworkconnecting nature and people. Curr Opin Environ Sustain. 2015;14:1-16.

Dumais D, Prévost M. Management for red spruce conservation in Québec: the importance of some physiological and ecological characteristics - a review. For Chron. 2007:83:378-91.

Dutta PK, Das AK, Sundriyal RC. Alpine timberline research gap in Himalaya: a literature review. Indian Forester. 2014;140:419-27.

Engler R. Migclim user guide (for R). Migclim R user guide. Version 1.1.0; 2012. p. 31.

Engler R, Guisan A. MigClim: predicting plant distribution and dispersal in a changing climate. Divers Distrib. 2009;15:590-601. 
Engler R, Hordijk W, Guisan A. The MIGCLIM R package - seamless integration of dispersal constraints into projections of species distribution models. Ecography. 2012;35:872-8.

Golicher DJ, Cayuela L, Newton AC. Effects of climate change on the potential species richness of Mesoamerican forests: effects of climate change on potential species richness. Biotropica. 2012;44:284-93.

Guillera-Arroita G, Lahoz-Monfort JJ, Elith J, et al. Is my species distribution model fit for purpose? Matching data and models to applications: matching distribution models to applications. Glob Ecol Biogeogr. 2015;24:276-92

Hartley S, Harris R, Lester PJ. Quantifying uncertainty in the potential distribution of an invasive species: climate and the Argentine ant. Ecol Lett. 2006;9:1068-79.

Heide OM. High autumn temperature delays spring bud burst in boreal trees, counterbalancing the effect of climatic warming. Tree Physiol. 2003;23:931-6.

Higgins SI, Cark JS, Nathan R, et al. Forecasting plant migration rates: managing uncertainty for risk assessment. J Ecol. 2003;91:341-7.

IPCC. Intergovernmental panel on climate change. Summary for policymakers. In: Stocker TF, Qin D, Plattner GK, et al., editors. Climate change 2013: the physical science basis. Cambridge and New York: Contribution of Working Group I to the Fifth Assessment Report of the Intergovernmental Panel on Climate Change; 2013.

Kong WS. The alpine and subalpine geoecology of Korean Peninsula. Korean J Ecol. 1998;21:383-7.

Kong WS. Biogeography of Korean plants. Seoul: Geobook; 2007. p. 355

Kong WS, Kim G, Lee SG, et al. Vegetation and landscape characteristics at the peaks of Mts. Seorak, Jiri and Halla. 2017:8:401-14 [Korean, abstract in English].

Kong WS, Kim K, Lee S, et al. Distribution of high mountain plants and species vulnerability against climate change. J Environ Impact Assess. 2014;23:119-36.

Koo KA, Kong WS, Nibbelink NP, et al. Potential effects of climate change on the distribution of cold-tolerant evergreen broadleaved woody plants in the Korean Peninsula. PLoS One. 2015;10:e0134043.

Koo KA, Kong WS, Park SU, et al. Sensitivity of Korean fir (Abies koreana Wils.), a threatened climate relict species, to increasing temperature at an island subalpine area. Ecol Model. 2017:353:5-16.

Korea National Arboretum. Distribution maps of vascular plants of Korean Peninsula I. Pocheon: South coast province. Korea National Arboretum; 2004

Korea National Arboretum. Distribution maps of vascular plants of Korean Peninsula II. Pocheon: South province (Jeollado \& Jirisan). Korea National Arboretum; 2005

Korea National Arboretum. Distribution maps of vascular plants of Korean Peninsula III. Pocheon: Central \& South province (Chungcheong-do). Korea National Arboretum; 2006

Korea National Arboretum. Distribution maps of vascular plants of Korean Peninsula IV. Pocheon: Central \& south province (Gyeongsangbuk-do). Korea National Arboretum; 2007.

Korea National Arboretum. Distribution maps of vascular plants of Korean Peninsula V. Pocheon: Central province (Geonggi-do). Korea National Arboretum; 2008

Korea National Arboretum. Distribution maps of vascular plants of Korean Peninsula VI. Pocheon: Central province (Gangwon-do). Korea National Arboretum; 2009a.

Korea National Arboretum. Distribution maps of vascular plants of Korean Peninsula VII. Pocheon: South province (Gyeongsangnam-do) and Ulleungdo province. Korea National Arboretum; 2009b.

Korea National Arboretum. Distribution maps of vascular plants of Korean Peninsula IX. Pocheon: West \& South coast province. Korea National Arboretum; 2011

Korea National Park Service (2018). Korea National Park Service 22, Hyeoksin-ro, Wonju-si, Gangwon-do, Korea. http://knps.or.kr. Accessed 05 Oct 2018.

Lee SG. Effects of temperature increases on the distribution of plants and vulnerability analysis. Kyunghee University, South Korea: MS Thesis; 2011. p. 284.

Lobo JM, Jiménez-Valverde A, Real R. AUC: a misleading measure of the performance of predictive distribution models. Glob Ecol Biogeogr. 2008; $17: 145-51$

Miller K, Hyun K (2009). Ecological corridors: legal framework for the Baekdu Daegan Mountain System (South Korea). South Korea 13.

Ministry of Environment (2018). Ministry of Environment, Republic of Koreaclimate change outlook. http://eng.me.go.kr/eng/web/index.do?menuld=220. Accessed 23 Sep 2018.

Myking T, Heide OM. Dormancy release and chilling requirement of buds of latitudinal ecotypes of Betula pendula and B. pubescens. Tree Physiol. 1995;15:697-704.
National Institute for Environmental Research. The second and third national ecosystem survey: 1997-2012. Incheon: National Institute of Environmental Research; 2013

Noh I, Chung JM, Cho MG, et al. The flora of subalpine vascular plants in Seseok area of Jirisan National Park, vol. 8; 2017. p. 201-11.

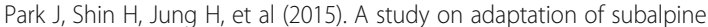
ecosystem to climate submitted to change. A reported submitted to National Institute of Ecology, Korea. [Korean, abstract in English].

Park SU, Koo KA, Hong S. Climate-related range shifts of Ardisia japonica in the Korean Peninsula: a role of dispersal capacity. J Ecol and Environ. 2017:41:38.

Park SU, Koo KA, Kong WS. Potential impact of climate change on distribution of warm temperate evergreen broad-leaved trees in the Korean Peninsula. J Korean Geographical Soc. 2016a;51:201-17 [Korean, abstract in English].

Park SU, Koo KA, Seo C, et al. Potential impact of climate change on distribution of Hedera rhombea in the Korean Peninsula. J Climate Change Res. 2016b;7: 325-34 [Korean, abstract in English].

Pearsons RG. Species distribution modeling for conservation educators and practitioners. Lessons in Conservation. 2010;3:54-8.

Portnoy S, Willson MF. Seed dispersal curves: behavior of the tail of the distribution. Evol Ecol. 1993;7:25-44

Pramanik M, Paudel U, Mondal B, et al. Predicting climate change impacts on the distribution of the threatened Garcinia indica in the Western Ghats, India. Climate Risk Manag. 2018;19:94-105.

Rixen C, Dawes MA, Wipf S, Hagedorn F. Evidence of enhanced freezing damage in treeline plants during six years of $\mathrm{CO}_{2}$ enrichment and soil warming. Oikos. 2012;121:1532-43.

Robert JH, Steven P, John L et al (2017). Package'dismo'. https://cran.r project.org/ web/packages/dismo. Accessed 23 Sep 2018.

Sevanto S, Suni T, Pumpanen J, et al. Winter time photosynthesis and water uptake in a boreal forest. Tree Physiol. 2006;26:749-57.

Shin MS, Changwan S, Park SU, et al. Prediction of potential habitat of Japanese evergreen oak (Quercus acuta Thunb.) considering dispersal ability under climate change. J Environ Impact Assess. 2018;27:291-306 [Korean, abstract in English].

Swets J. Measuring the accuracy of diagnostic systems. Science. 1988:240:1285-93.

Thuiller W, Lavorel S, Araujo MB. Niche properties and geographical extent as predictors of species sensitivity to climate change. Glob Ecol Biogeogr. 2005; 14:347-57.

Vellend M, Myers JA, Gardescu S, et al. Dispersal of trillium seeds by deer: implications for long distance migration of forest herbs. Ecology. 2003;84: $1067-72$

Ready to submit your research? Choose BMC and benefit from:

- fast, convenient online submission

- thorough peer review by experienced researchers in your field

- rapid publication on acceptance

- support for research data, including large and complex data types

- gold Open Access which fosters wider collaboration and increased citations

- maximum visibility for your research: over $100 \mathrm{M}$ website views per year

At $\mathrm{BMC}$, research is always in progress.

Learn more biomedcentral.com/submissions 